\title{
Design and Optimization of 200 Ton H- Type Hydraulic Press
}

\author{
G. Jamuna Rani ${ }^{*}$, Gangadhara Rao. $\mathrm{P}^{2}$, Konuru Srinivasa $\mathrm{Rao}^{3}$, M. Ravi Teja ${ }^{4}$ \\ ${ }^{1}$ Assistant Professor, Department of Mechanical Engineering, V. R. Siddhartha Engineering College, Vijayawada, India. \\ ${ }^{2}$ Associate Professor, Department of Mechanical Engineering, Aditya College of Engineering and Technology, Surampalem, India. \\ ${ }^{3}$ Assistant Professor, Department of Mechanical Engineering, Vidya Jyothi Institute of Technology,Hyderabad, Telangana, India \\ ${ }^{4}$ UG Student, Department of Mechanical Engineering, V. R. Siddhartha Engineering College, Vijayawada, India
}

\begin{abstract}
A hydraulic press is a machine using a hydraulic cylinder to generate a compressive force. The hydraulic press works on Pascal's principle, which states that the pressure throughout a closed system is constant. Hydraulic presses are commonly used for forging, clinching, moulding, blanking, punching, deep drawings and metal forming operations.200-ton capacity hydraulic frame and cylinder are modelled using Solidworks and analysed by solidworks simulation using finite element analysis. The objective of the project is to optimize the total mass and cost of hydraulic press while assuring adequate stiffness by using honeycomb structure on ram. Honey comb structures allows the minimization of material used to reach minimal weight and minimal material cost by providing high strength without compromising the output quality.
\end{abstract}

\section{INTRODUCTION:}

Today, the advanced technologies lead to the modifications in the mechanical engineering design, analysis and optimisation of various mechanical devices. Further the functional requirement, performance, reliability, weight and reasonable cost are some of the major factors need to consider in the design of any mechanical device. The compromised solution among these factors leads to the Optimization in every mechanical engineering design.In the recent days hydraulic presses are designed to increase their efficacy, Prabaharan et al., presented the work on the optimisation of 5 ton hydraulic press for cost reduction. Their work, showed $25.26 \%$ cost reduction in the scrap baling press, and are fabricated5ton hydraulic press [1]. Saleh et al., investigated design analysis of 150-ton hydraulic press using LUSAS finite element analysis. The work concludes the good agreement between the experimental modal and the proposed analytical modal. Also, the work discusses optimisation design with minimum time and lower cost.[2]. Another new method called novel sensitivity analysis method applied to find the performance of hydraulic press by Zhu et al., this method saves a lot of design time and cost[3].Parmar et al., has done the optimisation of a limited components of 200 Tonhydraulic press,such as top plate, movable plate, and columns the work demonistrate the generation of batch files by CREO and analysis is done using ANSYS for the mentioned components[4].Vinubhai et al.,worked on design and sizing optimization of hydraulic press reduced the weight quite significantly and observed the increase in values of deformation and stress and they were under permissible values for safe design[5].The study on C-type power press with a capacity of 10 tons was done by Ravi under static conditions by 3D modelling and analysed to find the stresses and deflections in the structure and reduced the weight of the press by varying the thickness of bed and frame [6].Kulkarni performed the finite element analysis andreduced the cost of the hydraulic press by optimizing the volume of the material utilized for building the body and in final the total percentage reduction in weight ofboth heads and the frame is $21 \%$ and $64 \%$. They observed drastic reduction in weight of the frame [7].Kamate designed and analysed a 20Ton hydraulic press and optimized the existing press by using finite element analysis software and weight of new hydraulic press and was reduced up to $53.48 \%$ and the stresses induced in new hydraulic press was within the limit[8].Sezen etal., chosen 300Tons hydraulic press for structural analysis of press body parts based on geometric optimization using finite element analysis and performed linear static analysis,maximum von miss stress locations, the obtained results are useful and realistic for the press manufacturer company to decrease raw material for press production [9].Aydin etal., designed Hydraulic press under distinct loading conditions using finite element analysis with a capacity of $250 \mathrm{KN}$ with the different types of press columns and heads to minimize the stresses and displacements under different loading conditions. The stresses and displacements are calculated using both analytical and FEA method. In the numerical FEA calculations, finite element method is employed successfully along with both beam and plane elements in the models[10]. Sinhaet al., designed c-type hydraulic press based on computer

*Corresponding author : jamunarani.g@gmail.com 
aided design,this decreases the computational time approximately $70 \%$, core memory requirement and cost of analysis[11].Thomasetal., studied crushing behaviour of Honeycomb structure and it was found to be very effective for crashworthiness, the conclusions shows the strength of honeycomb structure depends on the type and phenomenon of load acting, geometric properties such as node length, cell size, cell wall thickness [12].

Geometrical core configuration and geometric property like cell size, cell wall thickness and node length etc.

\section{MATERIAL SELECTION:}

EN24 Carbon steel is a high strength steel alloy, and is available in hardened and tempered state. The chemical composition is given in the following table1.This steel widely used in high strength shafts, gears, punches and dies, drill brushings and retaining rings [13].This alloy has good machining properties, it has unique combination of strength,ductility, wear resistance, and it is suitable for some applications at elevated temperatures. The machining properties and material properties are shown in Table2.

Table 1.EN24T Chemical composition (weigh \%)

\begin{tabular}{|l|l|l|l|l|l|l}
\hline Element & $\mathrm{C}$ & $\mathrm{Si}$ & $\mathrm{Mn}$ & $\mathrm{P}$ & $\mathrm{S}$ & \\
\hline Min. & 0.36 & 0.10 & 0.45 & & - & \\
\hline $\max$ & 0.44 & 0.35 & 0.70 & 0.035 & 0.04 & \\
\hline
\end{tabular}

Table2.Material properties of EN24T Steel.[13]

\begin{tabular}{|l|l|l|}
\hline S.no & Domain & property \\
\hline 1 & Name & $\begin{array}{l}\text { Plain carbon } \\
\text { steel }\end{array}$ \\
\hline 2 & Model type & $\begin{array}{l}\text { Linear elastic } \\
\text { isotropic }\end{array}$ \\
\hline 3 & Tensile strength & $350-370 \mathrm{Mpa}$ \\
\hline 4 & Yield strenth & $200-300 \mathrm{Mpa}$ \\
\hline 5 & Poissons ratio & $210 \mathrm{Mpa}$ \\
\hline
\end{tabular}

\begin{tabular}{|l|l|l|}
\hline 7 & Mass density & $7800 \mathrm{Kg} / \mathrm{m}^{3}$ \\
\hline 8 & Shear modulus & $790 \mathrm{Mpa}$ \\
\hline 9 & $\begin{array}{l}\text { Thermal } \\
\text { coefficient }\end{array}$ & $1.3 \times 10^{-5} \mathrm{~K}^{-1}$ \\
\hline
\end{tabular}

\section{MODELLING and Meshing}

Modelling and assembly of press components are done in solidworks. Modelling is one of the major aspects to be considered during designing as it helps to picturise and simulate various forces and the effects of those forces that the tool will experience after fabrication. Subcomponents are designed while taking into consideration variables which could affect the stress distribution of the machine both individually and as a whole. The subcomponents of hydraulic press are shown in Figure. 1 experience a number of forces of varying ndares anCffrom varying directions. During designing a bottgm to top approach 30 must be taken. While designing the. 35 model it is required to simulate worst case scenarios using various software's to test the validity and compactness of the design.

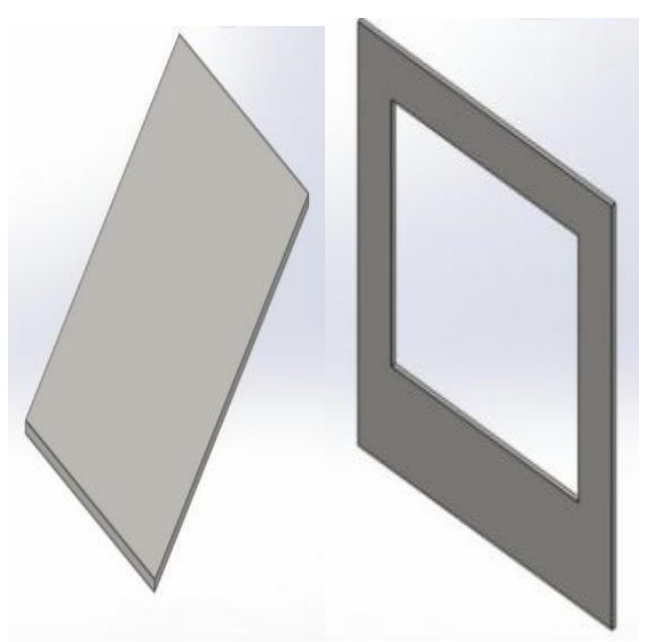




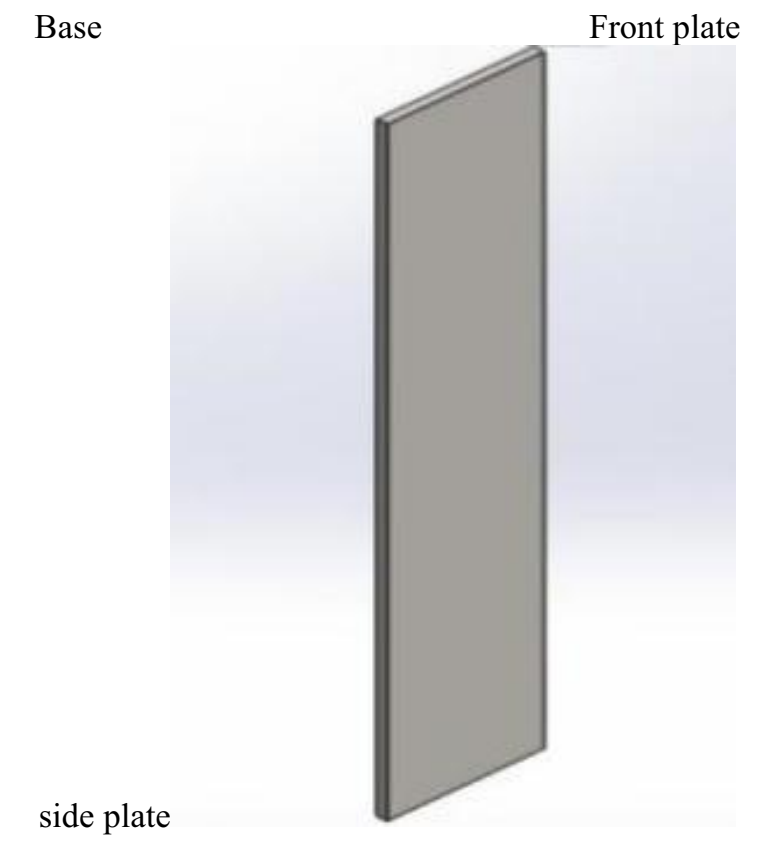

Ram with Honeycomb structure

\section{Fig.1: Sub Components of Hydraulic press}

Among the weight reducing techniques one of the best method is honeycomb structures these are natural or manmade structures. These structures are allowed to reduce amount of material used for the same load carrying capacity of the component. This is due to geometry of the structure made it to withstand compressive strength along the axial as well as lateral direction of the structure. Honeycomb structures are prominently used when maximum load carrying capacity with minimum material criteria. This structure configuration is generated with the primitive elements of hexagon, triangular, square, circular, and this is decided by the strength to amount of material ratio. The honey comb structure performance is depends on the geometrical parameters such as cell size, cell wall thickness, node length and cell configuration. [15]After modelling the sub components, they are assembled to form the hydraulic press as shown in Fig.2 with honeycomb structured ram with adequate stiffness and strength.

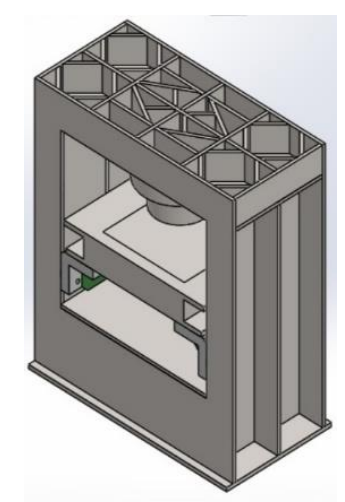

Fig.2: Assembly of hydraulic press with honeycomb structured ram

The way of splitting the entire model into number of tiny elements to analyse the load bearing phenomenon is known as meshing. Finite Element Analysis (FEA) program interprets the entire meshed geometry model in to a network of orderly interconnected elements. The process of carefully generated geometric modelling and meshing will play critical role in the design analysis. The solid works software generates mixed mesh model with shell and beam elements automatically for given set of inputs.

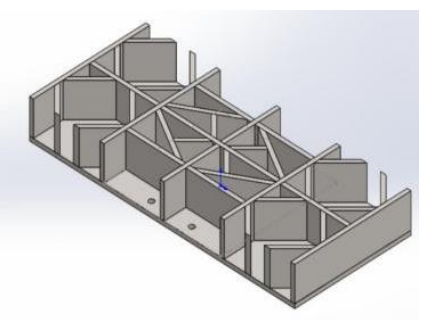




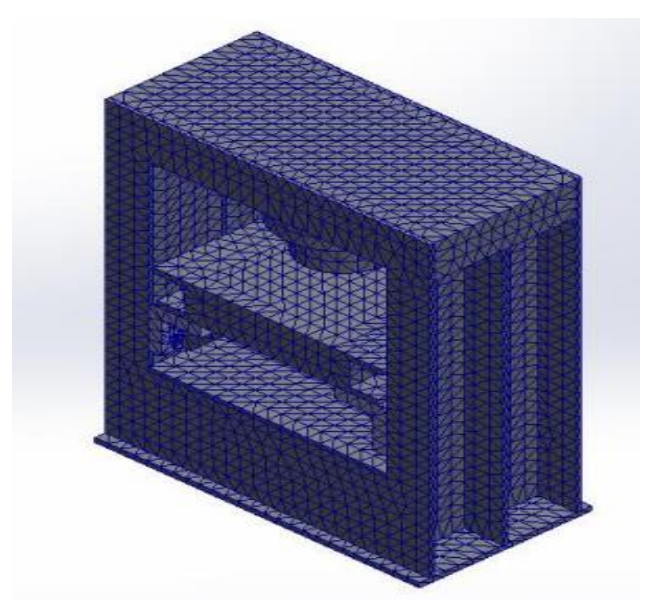

Fig.3 : Solid meshing of solid slab hydraulic press in solidworks

\section{RESULTS FROM STATICANALYSIS:}

When loads are applied to a body, itdeforms and the effect of total loads is transmitted throughout the body. Linear Static analysis calculates strains, stresses, displacements and reaction forces under the effect of applied loads. The von Mises' theory states that a ductile solid will yield when the distortion energy density reaches a critical value for that material. The equivalent stress of the material before its distortional energy (Change in shape only) reaches its yielding point is represented by von Mises stress $(\sigma \mathrm{VM})$ and is shown in Fig.4, [14].

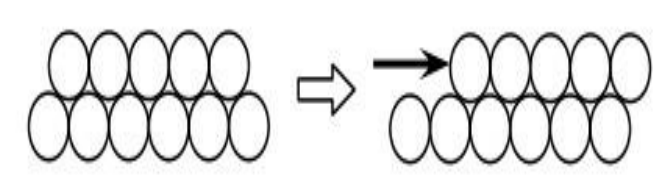

Fig.4: Distortion energy

\subsection{Stress analysis:}

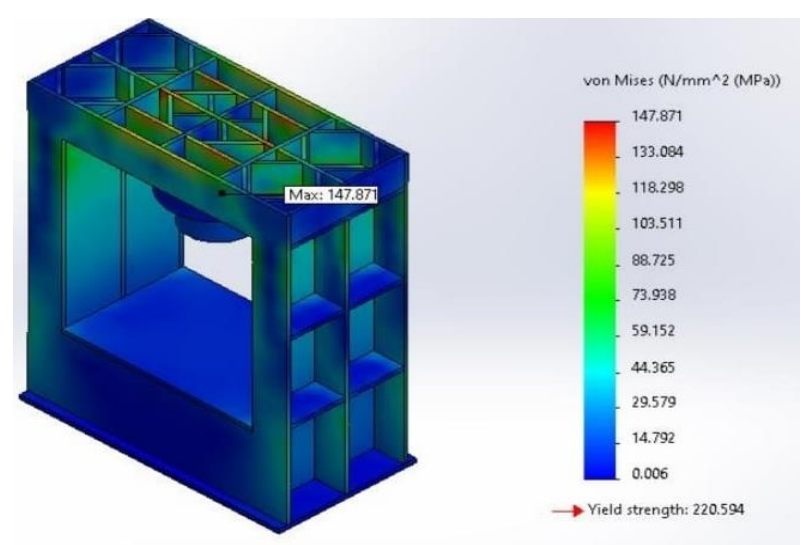

Fig. 5: Stress analysis of HP with Honeycomb ram

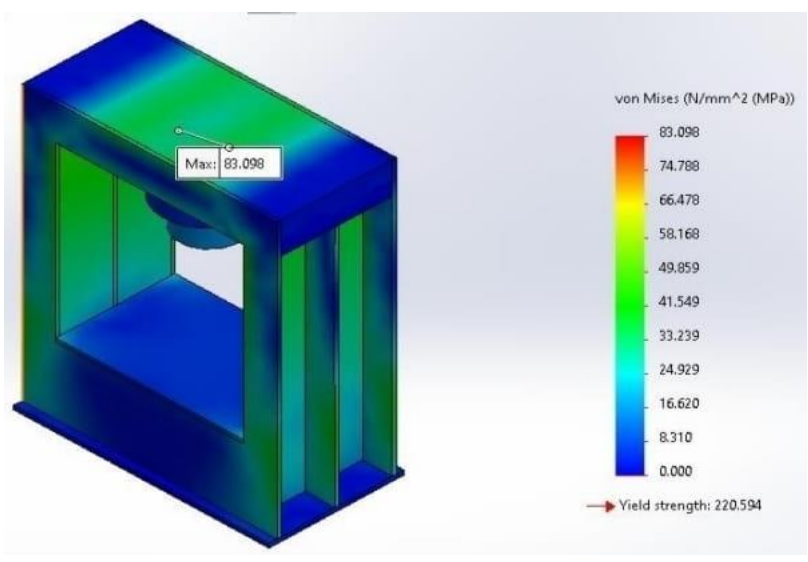

Fig.6: Stress analysis of HP with solidslab ram

After performing static analysis of the hydraulic press with solid ram and honeycomb ram structure in solidworks simulation, maximum stress values obtained are $83.098 \mathrm{~N} / \mathrm{mm}^{2}$ and $147.871 \mathrm{~N} / \mathrm{mm}^{2}$ respectively as shown in Fig.5\&6. The maximum stresses induced in the 200 ton hydraulic press is less than the permissible stress of the material ,but while considering the factor of safety values we got 1.49 and 2.65 for hydraulic press with honeycomb ram structure and solid slab structure.Here, for hydraulic press with honeycomb ram we got safe factor of safety value is less than permissible values,so design is safe and ready to use,but for hydraulic press with solidslab ram we gotfactor of safety is 2.65(>>1)hence it is overdesign and not safe.

\subsection{Deformation analysis}

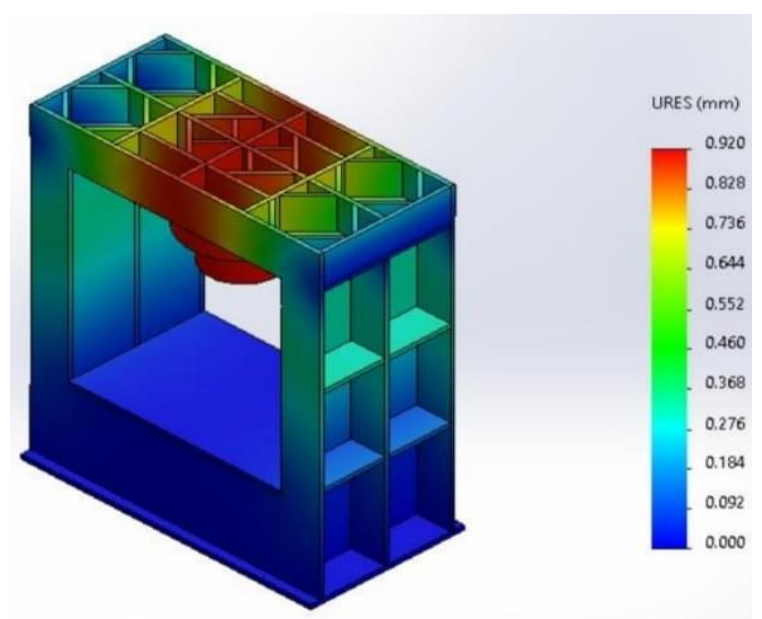

Fig.7:Deformation analysis of HP with Honeycomb ram 


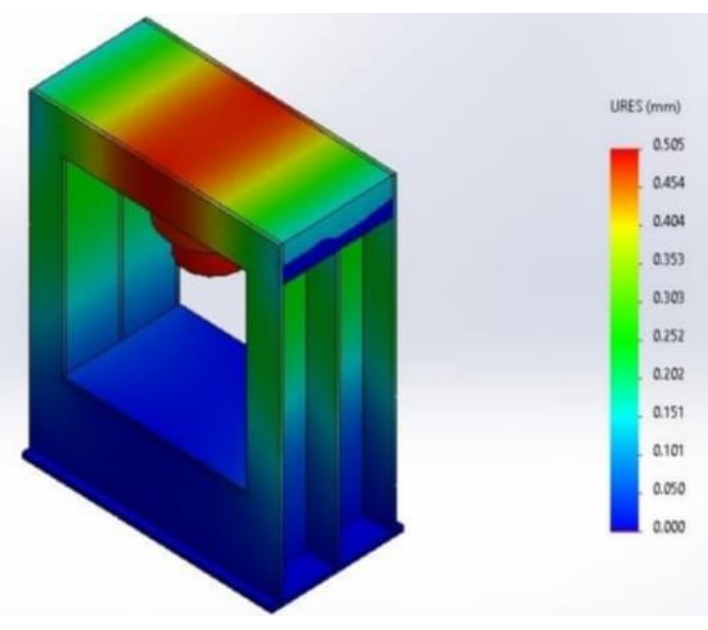

Fig.8: Deformation analysis of HP with solidslab ram.

after performing static analysis of the hydraulic press with honeycomb ram structure and solid slab ram structure in solidworks simulation, maximum displacement values obtained are as $0.920 \mathrm{~mm}$ and $0.505 \mathrm{~mm}$ as shown in Fig.7\&8.As analysis shows maximum deformation found is lesser than $1 \mathrm{~mm}$ for hydraulic press with honeycomb ram structure and solidslab ram structure which is tolerable for such hydraulic pressing operations. Hence design is ready to use.

5.Calculation of Cost Reduction for Hydraulic Press: The 200tonn hydraulic press was designed and analyzed by considering necessary standards and performed the cost estimation for manufacturing by considering the cost of material for plain carbon steel and also cost for the fabrication of hydraulic press Material cost per $\mathrm{kg}$ asRs.75/- and Fabrication cost per kg as Rs.48/-.
5.1 Cost of Hydraulic Press with solid-slab RAM structure:

Material cost for $6361.3 \mathrm{~kg}=\mathrm{Rs} .4,77,098$

Fabrication cost for $6361.3 \mathrm{~kg}=$ Rs.3,05,343

Total cost $=$ Material cost + Fabrication cost $=$ Rs. 7,82,441.

5.2 Cost of Hydraulic Press with honey-comb RAM structure:

Material cost for $5129 \mathrm{~kg}=$ Rs.3,84,669

Fabrication cost for $5129 \mathrm{~kg}=$ Rs. $2,46,188$

Total cost $=$ Material cost + Fabrication cost $=$ Rs.6,30,857.

$\%$ of material cost reduction $=\{($ Total cost before optimization-Total cost after optimization)/Total cost before optimization $\} * 100$

$=\{(782441-630857) / 782441\} * 100$

$=19.4 \%$

Percentage of cost reduction we got up to $19.4 \%$. 
Table 2.Comparision of hydraulic press before and after optimization

From the above comparison of results as shown in Table 2 , we can conclude that the hydraulic press with ram having solid-slab structure is said to be over designed because of its factor of safety $(n=2.65)$ is high. Hence, we considered the hydraulic press with ram having honey comb structure as safe design.

\section{Conclusion :}

:Anattempt has been made to design, analyse and optimize the existing hydraulic press with solid ram using solidworks without compromising the output quality. After the design and analysis, it has been observed that the hydraulic press with honey comb structured ram cost was reduced up to $19.4 \%$ by changing the design of existing hydraulic press solid slab ram with honeycomb structure ram and by keeping the remaining sub components same. The stresses induced in Hydraulic press with honey comb structured ram is in within the limit and is safe to manufacture and use in industries.

\section{References}

Prabaharan, Muni, and V. Amarnath, "Structural optimization of 5ton hydraulic press and scrap baling press for cost reduction by topology", International Journal of Modeling and Optimization 1.3 (2011): 185.

Saleh, Mohamad M. Design study of a heavy duty hydraulic machine using finite element techniques. Diss. Dublin City University, 1992.

Zhu, Peihao, Lianhong Zhang, Rui Zhou, Lihai Chen, Bing Yu, and QizhiXie. "A novel sensitivity analysis method in structural performance of hydraulic press." Mathematical Problems in Engineering 2012 (2012).

Parmar, Ankit H., Kinnarraj P. Zala, and Ankit R. Patel. "Design and modification of foremost element of hydraulic press machine." International Journal of Advanced Scientific and Technical Research 4 (2014).

Vinubhai, Patel Shreyash Kumar, and Pritesh Prajapati. "Design and Modification of Foremost Element of Hydraulic press Machine.".

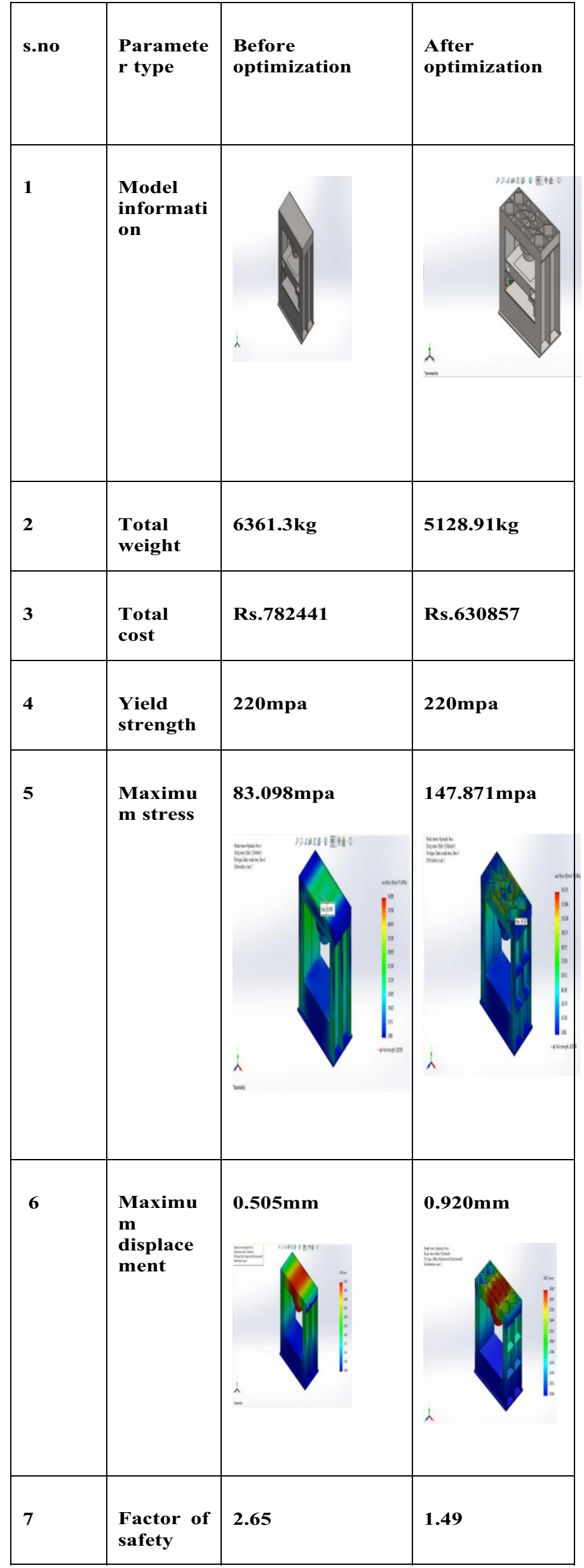


Ravi, D. "Computer Aided Design and Analysis of Power Press." Middle-East Journal of Scientific Research 20.10 (2014): 1239-1246.

Badakundri, Umesh S., Santosh Kullur, and A. A. Kulkarni. "Finite Element Analysis of Hydraulic Press Machine." International Journal on Recent Technologies in Mechanical and Electrical Engineering 2, no. 5.

Kamate, ASIM M. "Design, Development and Analysis of a 20 Ton Hydraulic Press." International Journal of Innovative Technology and Research 4 (2016): 2560-2563.

SEZGEN, HAȘMET ÇAĞRI, ABDULLAH ÇAKAN, And MUSTAFA TINKIR. "Linear Buckling Analysis of Cylinder Rods Used on Industrial 300 Tons H-Type Hydraulic Press." (2017).

Aydin, Mehmet, and Yasin Kisioglu. "Hydraulic press design under different loading conditions using finite element analysis." Engineering Science \& Technology, an International Journal 16, no. 3 (2013)..

Sinha, S. P., and P. D. Murarka. "Computer-aided design of hydraulic press structures." Mathematical and Computer Modelling 10.9 (1988): 637-645.

Thomas, Tiju, and Gaurav Tiwari. "Crushing behavior of honeycomb structure: a review." International journal of crashworthiness 24.5 (2019): 555-579.

https://www.steelexpress.co.uk/engineeringsteel/EN 24T-properties.html

Timoshenko, S. (1953). History of strength of materials. New York: McGraw-Hill.

Tiju Thomas \& Gaurav Tiwari (2019): Crushing behavior of honeycomb structure: a review, International Journal of Crashworthiness, DOI:10.1080/13588265.2018.1480471. 